\title{
Analysis on Practical Application and Construction Process of Grouting Technology in Architectural and Civil Engineering
}

\author{
Gang $\mathrm{Li}^{1}$, Bo Huang ${ }^{2}$ \\ ${ }^{1,2}$ Xinyang Vocational and Technical College, Xinyang Henan , 464000,China
}

\begin{abstract}
Key words: Architectural and civil engineering, Grouting technology, Practical application, Construction technology.
\end{abstract}

\begin{abstract}
In the construction industry, the construction quality and safety attract a widespread attention, and such problems are also critical in this industry. The acceleration of urbanization in our country results in ever-increasing construction problems, among which crack and leakage are more common. Thus, architectural technicians are required to apply the grouting technology for the work execution, pay attention to material quality problem concerning the grouting technology, and introduce newly-emerging techniques. On the basis of studying the grouting technology involved in architectural and civil engineering, this paper analyzes the characteristics of various construction technologies and put forward several strategies about application of grouting technology, to provide reference for relevant personnel.
\end{abstract}

\section{Introduction}

The crack problem occurs frequently in the architectural and civil engineering, is the most common problem in the development of architectural and civil engineering, and attracts a widespread attention from all circles of the society. Especially in high-rise buildings, the crack problem happening to living quarters will bring adverse impact on people's daily life, and that happening to office area will cause adverse effect on people's work; besides, the crack problem happening to stock area will not only cause bad effect on the economic benefit of the stock-keeping unit, but also bring huge loss to the construction unit. Therefore, related technicians should pay high attention to the application of grouting technology and take effective measures for improving the application quality, so as to lay a good foundation for its development.

\section{Causes of crack problem in architectural and civil engineering}

The crack problem occurs frequently during construction of civil works, bringing adverse effect on economic benefit of the construction unit. Therefore, related technicians should focus on analyzing the causes of the crack problem, so as to enhance the construction quality of civil works in a better way. The causes include: reinforced concrete is often selected as the main material during construction of civil works to reduce the cost. Although the reinforced concrete is good in strength and stability and has a long service life, its biggest disadvantage is the easy occurrence of crack problem during its practical application. After the occurrence of crack problem, it is very difficult for buildings to provide normal services. After study and analysis, relevant researchers found that there are many reasons causing the crack of reinforced concrete, including: architectural structure, quality of building materials, etc. The crack problem of architectural structure means that concrete structure has cracks after the building carries a heavy load exceeding the carrying capacity of the concrete. The crack problem of building materials means that the crack problem occurs in the process of concrete shrinkage during temperature variation due to loss of too much water of concrete reinforcement materials; during concrete shrinkage, the great change of shape occurs, resulting in increasingly 
serious crack problem. Meanwhile, the research by relevant technicians shows that, under certain humidity contrast, reinforced concrete will have shrinkage and cracks, bring adverse effect on its quality. Besides, the causes of crack problem in architectural and civil engineering also include human factors: construction technicians or construction teams could not discover problems timely due to poor technical abilities, thus it is difficult to guarantee the quality of architectural and civil engineering.

\section{Analysis on grouting technology}

\section{Static grouting}

During construction of architectural and civil engineering, the soft soil foundation will often split off, which requires the static grouting technology to resolve such problem. Grouting technology itself has unique characteristics such as great pressure; the static grouting technology can be utilized at the base course of soft soil foundation and other weak places to achieve the extension and the formation of favorable concretion, to improve the quality of soft soil foundation in a better way. In this process, the concretion can be taken as the skeleton of soft soil foundation to protect surrounding soil layer and consequently enhance the carrying capacity of soft soil foundation, reduce the splitting problem and improve the construction problem of soft foundation ${ }^{[1]}$.

\section{High-pressure jet grouting}

The concrete crack problem occurs frequently in the construction of civil works, which results in adverse effect on construction quality; thus, relevant technicians require the grouting technology to resolve such problem. At this time, the high-pressure jet grouting method may resolve the crack problem in a better way. At present, the high-pressure jet grouting method is widely used in water conservancy projects to enhance the project quality in a better way. Meanwhile, it is also used in strengthening the soft soil foundation to effectively enhance the carrying capacity of foundation. Besides, the high-pressure jet grouting method can be also used in construction of civil works, especially in construction of high-rise buildings, to enhance the waterproofness of concrete reinforcement structure in a better way and avoid the difference in quality and the crack problem due to rainwater invasion.

\section{Composite grouting}

Currently, the crack problem often occurs in construction of civil works, causing adverse effect on its development. Thus, the grouting technology is required to resolve such problem. In the process of applying the grouting technology, the composite grouting method is important and generated through combination of static grouting and high-pressure jet grouting. Before use of the composite grouting method, it is required to utilize the high-pressure jet grouting to let cement form a solid volume, and then adopt the static grouting method to spread the grout, guaranteeing the grout flowing into the concrete reinforcement structure without grouting dead zone. This method is widely applied for both floury soil and fine sand and has an extremely strong grouting effect, which is beneficial to enhancing the application quality of grouting technology ${ }^{[2]}$.

\section{Advantages of grouting technology}

In recent years, construction units place too much emphasis on their own interests and neglect the civil engineering construction quality due to fast development of civil engineering construction, which results in the situation that it is difficult to resolve the crack problem and enhance the construction quality of civil works; to some extent, it will bring serious effect on economic benefits of construction units. Through analysis, related researchers learned that the grouting technology is beneficial to resolving the crack problem of civil works because of its advantages listed below: 


\section{Simple construction process}

In the construction process of civil works, grouting technology has the advantage of simple construction process, which is beneficial to dealing with the crack problem of civil works mainly because small construction equipment related to grouting technology can be easily transferred and carried by relevant technicians and well used by technicians to execute the grouting technology in the complex environment on construction site, so as to effectively resolve the crack problem, reduce the construction cost and lay a foundation for development of construction units ${ }^{[3]}$.

\section{Enhancing the strength of buildings}

The grouting technology applied to concrete structure can effectively enhance the strength of buildings; this is mainly because the grouting technology executes the grouting at places where concrete may crack easily, so as to deal with its internal cracks in a better way, effectively improve the internal structure of concrete, enhance the concrete density and strength, and play a powerful bonding role in internal structure of concrete; it can not only effectively deal with the crack problem, but also avoid the reappearance of crack problem and bring positive effect on its development ${ }^{[4]}$.

\section{Obvious advantages of grouting technology}

During construction of architectural and civil works, the application advantages of grouting technology are obvious. Firstly, the materials used in grouting technology have certain chemical properties that can improve the comprehensive capabilities of concrete reinforcement structure; secondly, the grouting technology itself has certain cohesive property that can deal with the crack problem in a better way, form a favorable anti-compressive structure after application of grouting technology, and bring positive effect on preventing crack problems; lastly, the grouting technology applied can prolong the service life of concrete reinforcement structures in civil works and consequently reduce building quality problems. Besides, the application of grouting technology can reduce environmental pollution from civil works, decrease the impact on construction in a better way, has an obvious reinforcement effect, and bring positive effect on development of civil works ${ }^{[5]}$.

\section{Application strategies of grouting technology in civil works}

The application of grouting technology in civil works can effectively enhance the carrying capacity of concrete reinforcement structure, improve the construction efficiency of civil works and is beneficial to its better development. In this process, relevant technicians can have a better analysis on civil works, take effective measures for application of the grouting technology, and enhance the construction quality of civil works. The specific application measures include:

\section{Paying attention to purchase of grouting technology application materials}

In the application process of grouting technology in architectural and civil works, relevant management personnel should pay attention to the material purchase work; this is mainly because the quality of grouting materials has a direct impact on application efficiency of grouting technology. Therefore, relevant management personnel must pay attention to procurement of grouting technology materials. In general, materials adopted for grouting technology in civil works include: cement, water glass slurry, organic polymer materials, etc. In the process of material inspection, purchasing personnel should pay attention to strength of materials and select those materials with a long service life according to the engineering needs; besides, materials should have unique chemical properties and better filling property. To improve the application efficiency of grouting technology, materials with strong permeability should be purchased to improve the bonding efficiency of construction joints and consequently enhance the application quality of grouting technology. Meanwhile, materials-purchasing personnel should also pay attention to pollution from materials and select those materials with less pollution to the einvronment, so as to improve the application efficiency. 


\section{Paying attention to selection of grouting methods}

The construction method of grouting technology in civil works is important, and relevant technicians should have a careful analysis on the construction site and select the grouting method according to specific condition on the construction site, so as to improve the application efficiency of grouting technology, reduce the application difficulty of grouting technology, effectively control the cost of the construction unit and lay a foundation for its development. The specific method is divided into the following points:

Way of basement grouting in civil works

During basement construction in civil works, cracks will often occur due to the structure problem. Basement is the place with most water pipes in the whole building, and the occurrence of leakage problem will have adverse impact on economic benefits of the construction unit. Therefore, relevant technicians should adopt an effective grouting method for the sensitive place. During grouting of the basement, effective measures should be taken according to the actual condition of the basement to confirm the cracking position, clear up the cracks by hole drilling and execute the high-pressure grouting technology, for the purpose of crack repair. After the repair, relevant technicians should inspect the construction site, and then announce the completion of grouting after confirming that there is no crack problem. To ensure application efficiency of grouting technology, relevant technicians should control the hole drilling depth; the hole drilling angle is not allowed to be perpendicular to the concrete surface; it is required to clear up cavities with high-pressure water, install grouting pipe orifices on cavities after clearing up them, ensure the connection tightness between grouting equipment and drilled holes, and avoid cracks that are adverse to construction quality. During the grouting process, the pressure of grouter should be controlled between 1.4 and 2.0, to avoid slurry cavity due to pressure problem.

Wall construction

In the construction process of civil works, the application of grouting technology in wall construction is an important work; the occurrence of wall cracks is resulted mainly from low professional quality of construction personnel who cannot control the material quality and density very well, resulting in wall cracks after environmental changes. Due to the unique properties of such problems, it is difficult to repair the cracks with general materials. Therefore, technicians should apply the grouting technology to repair the wall cracks. Wall crack grouting materials should have strong bonding, carrying and shear-resisting capacities, so as to repair cracks around doors and windows. Bottoms of doors and windows may crack easily due to various stresses; in the crack repair process of these positions, attention should be paid to reinforcing the bottom of wind frame, and the quality of cement must accord with relevant provisions, so as to enhance the wall density and anti-leaking capacity, reduce rainwater leakage and bring positive effect on improving the construction quality of architectural and civil works.

\section{Concrete structure construction}

During the concrete structure construction in architectural and civil works, the application of grouting technology can effectively increase the strength of concrete structure. Concrete structure is mainly applied on weight-carrying position, and the economic development of construction unit will be affected and serious consequences will be caused if the crack problem of such structure cannot be resolved timely. Therefore, relevant technicians should pay high attention to application of grouting technology and set the grouting aperture before grouting; the aperture size should be around 0.8mm, and an excessively small aperture will bring many inconveniences to construction. Distance between holes should be kept around $300 \mathrm{~mm}$, and the hole depth should be confirmed according to the actual condition of the crack. During construction, it is required to guarantee the evenness of grouting slurry and avoid flowing of slurry out of the crack repairing hole that will bring adverse impact on economic benefits of the construction unit. 


\section{Conclusion}

In architectural and civil works, the application of grouting technology is very important, and relevant technicians must pay attention to their own work and take effective measures to improve the application efficiency of grouting technology. Relevant construction units should pay attention to professional quality of technicians and periodically provide trainings related to professional knowledge for them, so as to let them apply the grouting technology in a better way.

\section{References}

[1] Liu Yanling. Application and Construction Process of Grouting Technology in Architectural and Civil Works, Jiangxi Building Materials, 2015 (19): 73-73.

[2] Zhou Qihua. Application and Construction Process of Grouting Technology in Architectural and Civil Works, Construction Materials and Decoration, 2015 (26): 55-56.

[3] Liu Xiaowei. Research on Application and Construction Process of Grouting Technology in Architectural and Civil Works, Architectural Engineering Technology and Design, 2015 (27): 81-81.

[4] Chen Peilin. Application and Construction Process of Grouting Technology in Architectural and Civil Works, Urban Construction Theory Research, 2014 (10).

[5] Zheng Haifang. Application and Construction Process of Grouting Technology in Architectural and Civil Works, Construction Materials and Decoration, 2015 (41): 47-48. 